\title{
What Enabled and Disabled First-year Pacific Student Achievement at University?
}

\author{
Tasileta Teevale \\ Alapasita Teu \\ Pacific Development \\ University of Otago
}

\begin{abstract}
Identifying positive success factors and addressing the factors that impede academic success for minority students in higher education, is a priority for most countries that are experiencing rapid population diversity. This qualitative study explored the experiences of first-year Pacific students at a New Zealand university, and undertook a comparative analysis of factors from two groups of students; one that successfully passed 50\% of their first-year papers compared with those students who did not pass at least $50 \%$ of their academic papers. Students who succeeded in the first year of study used Pacific-centric student support services, had family members who had been to University before, and had different study habits, learning strategies and expectations from their peers who struggled to achieve. This study identified important aspects of the first-year transition for Pacific students, upon which tertiary institutions can have some impact. As first-year academic success predicts University completion, this study recommends further effort in first year transition interventions to address the social and academic adaptations that Pacific students need to make in order to be successful at University study.
\end{abstract}

Key words: Pacific Island, students, minority, ethnicity, university, higher education, tertiary education, transition, first-year, New Zealand.

\section{Background}

In the New Zealand context, the term 'Pacific Peoples' refers to a grouping of multi-ethnic South Pacific migrants mainly from the Islands of Samoa, Cook Islands, Tonga, Fiji, Niue and Tokelau. These migrants have peopled New Zealand since the 1950s, through continuous migration as well as new generations being New Zealand-born. As a result, Pacific Peoples now make up $7.4 \%$ of the total New Zealand population (Statistics New Zealand, 2014). Upon closer inspection of population census data, Pacific Peoples in New Zealand have a much younger age-profile compared with the general population, with a little under half $(46.1 \%)$ being less than 20 years old, compared with $27.4 \%$ for the total population. The highest proportion of New Zealand children aged 0-14 years, at 35.7\%, are of Pacific ethnicity (Statistics New Zealand, 2014). As a fast-growing sector of the New Zealand population, New Zealand's future workforce is becoming more diverse, with increasing reliance on the contribution that Pacific tertiary graduates can make to the social wellbeing and economic success of New Zealand (Ministry of Education, 2013; Tertiary Education Commission, 2017).

These important demographic shifts have necessitated key educational policy objectives to prioritise the principle of success in education for all students at all levels. In the last decade, the number of Pacific Peoples entering into and succeeding at New Zealand universities has increased. The percentage of those with a bachelor's degree or higher rose from $5.4 \%$ to $8.9 \%$ between 2005 and 2015 but remains substantially below that of other New Zealand ethnic groups, namely New Zealand Europeans at 20.7\% and New Zealand's indigenous Maori at 9.9\% (Ministry of Education, 2015). In terms of tertiary qualifications completed within five years, 58\% of Pacific students completed their qualifications within five years of starting full-time study compared with $74 \%$ of all students (Meehan, Pacheco, \& Pushon, 2017). These figures indicate that educational disparities exist for Pacific students in New Zealand's tertiary education sector and there is a need to address this gap. This paper explores the university experiences of Pacific students at a New Zealand university, including identifying the enablers and barriers that contribute to academic achievement. 


\section{Literature review}

A current New Zealand tertiary education priority is to address issues of equity in education, with a particular focus on Pacific New Zealanders as a population group. A key outcome is to improve Pacific students' participation, retention and success in the tertiary sector, to at least on par with other students (Tertiary Education Commission, 2014). The issue of higher attrition and lower completion rates experienced by Pacific students compared with other population groups has received some attention; in particular, literature from the New Zealand (NZ) government sector which investigates Pacific students' educational achievement (Anae, Benseman, Anderson, \& Coxon, 2002; Horrocks, Ballantyne, Silao, Manueli, \& Fairbrother, 2012; Meehan, Pacheco, \& Pushon, 2017). A seminal report commissioned by the NZ Ministry of Education (2002) found that barriers to tertiary educational success, from the student perspective, included: feeling misunderstood by teaching staff; experiencing pedagogical practices that did not fit their expectations; not having locations in institutions that acknowledged Pacific identity and cultural knowledge; not seeing or accessing Pacific staff as role models; and not accessing particular types of learning support services. Also identified as important was the facilitation of a sense of belonging and being valued within an institution. Students interviewed for this study also indicated individual factors such as time management (for example, trying to manage numerous commitments such as family, church, parttime work, financial pressures), as barriers to educational achievement.

Recent NZ government-commissioned reports have contributed further evidence on barriers to success, highlighting that Pacific students are often first in their family to enter higher education (Chu, Abella, \& Paurini, 2013; Mayeda, Keil, Dutton, \& 'Ofamo'oni, 2016; Millard, Stephenson, Rio, $\&$ Anderson, 2011). There is also evidence that financial difficulties have significantly impacted on both participation and retention, with students dropping out of studies to find work to support their families (Luafutu-Simpson, Moltchanova, O'Halloran, Petelo, \& Uta'i, 2015; Toumu'a \& Laban, 2014). Recent studies have taken a more enabling approach, by investigating factors influencing success for Pacific students in tertiary education (Chu et al., 2013; Penn, 2010; Perrot, 2015). For example, one study found that Pacific students who were able to complete their tertiary studies stated that the culturally-responsive pedagogies at their institutions were critical to their success; this included learning material that acknowledged the worldview of students and incorporated Pacific models, metaphors and language (Airini et al., 2010). Another study found that having Pacific staff as role models enabled Pacific students to see tertiary institutions as a place for them (Benseman et al., 2006). Such studies have also found that having a visible Pacific presence on campus normalised Pacific culture and values in the institutions and made students feel welcomed and validated. This included having Pacific communities of learning such as Pacific student associations, tutorial groups, events, spaces, services and programs that promoted a Pacific presence on campus. These were highly valued by Pacific students and were seen as contributing to their success at higher education (Anae et al., 2002; Benseman et al., 2006; Chu et al., 2013).

Over the years, trends have shown improvements in Pacific participation in higher education, however, a closer examination of data reveals that this increase is largely attributed to low level certificates and diplomas in the tertiary sector (Benseman et al., 2006). This has influenced some recent work within particular fields such as Health Sciences, where efforts are being made to address the imbalance and to promote Pacific student success in specific professional fields such as medicine, nursing and other allied health professions (Kokaua, Sopoaga, Zaharic, \& van der Meer, 2014; Southwick, Scott, Mitaera, Nimarota, \& Falepau, 2017; Teu, 2014). These studies examining the experiences of Health Sciences Pacific students have confirmed much of what has been found previously in terms of barriers to achievement; however, an enabler for students has emerged, that of spirituality and, in particular, the Christian faith, which appears to be a source of support that has influenced positively Pacific student educational success (Ng Shiu, 2011). Research with Pacific 
Health Sciences students has also found that academic preparedness for university study impacts on their success (Sopoaga et al., 2013). This has highlighted the role of secondary schooling and pretransition settings in creating conditions that enable successful transitions from secondary schooling to tertiary education, particularly for professional university courses.

One study looking at the transition from secondary schooling to university study among students from low-mid decile ${ }^{1}$ schools in NZ, which included a cohort of Pacific students (who account for $90 \%$ of students from low-decile schools in NZ), illuminated the pre-transition and post-transition factors impacting on success (Madjar, Mckinley, Deynzer, \& van der Merve, 2010). Pre-transition factors included: the development of clear academic goals; strong academic preparation; realistic expectations of university; early planning of subjects related to intended post-secondary schooling goals; and a supportive family environment. Factors that appeared to be influential and important throughout post-transition, included: the level of success in the first year of university; accessing and utilising campus support services; and personal attributes such as determination, confidence, diligence and persistence (Madjar et al., 2010).

There is a vast international body of literature on the transition to university, stemming from the United States of America, United Kingdom and Australia, demonstrating that the first year of university is a pivotal time in a student's life (Tinto, 2006, 2008; Hillman, 2005; Yorke, 2000). The first year of study is described as a major life transition as new students make the passage from secondary schooling, employment and other aspects of their community, to university study. When entering university, students leave behind a particular secondary school system, community and environment. This can include leaving family, friends and familiar surroundings to embark upon uncharted territory (Kidwell, 2005). It also includes navigating through academic and non-academic challenges and demands, as students go through a transition period full of new learnings and social experiences (McInnis, 2000).

There is a handful of small qualitative studies on first-year student experiences in New Zealand universities, which suggest that institutional culture, support structures and the fostering of positive relationships are pivotal to student retention and to addressing early student departure (Madjar et al., 2010; Zepke et al., 2011). There is a paucity of published research worldwide on the transition from school to university for minority students, including Pacific students, which this paper addresses. The current literature, both local and international, points to the first year of study at university as a critical time-point for being successful at university study. Understanding the issues faced by underrepresented groups such as Pacific students in their first year of study, can illuminate strategies that the tertiary sector and the tertiary institutions within it, can develop to address their equity goals.

\section{Methods}

This study interviewed the cohort of Pacific students who entered the University of $\mathrm{Otago}^{2}$ in 2013. The authors of this paper interviewed participants post first year of study, using a qualitative approach to explore their first-year experiences. This included a follow-up of students who were no longer engaged in University study. Interview, as a type of qualitative data collection method, is "one of the most common and powerful ways in which we try to understand our fellow humans" (Fontana \& Frey, 2005, p. 698). It attempts to uncover and understand the subjects' point of view and the meanings placed upon their lived experiences (Kvale \& Brinkman, 2009). The interview process was

\footnotetext{
${ }^{1}$ In the NZ school system, a school's decile indicates the extent to which the school draws its students from low socioeconomic communities. Decile scale from 1-10, with decile 1 schools (or low decile) are the $10 \%$ of schools with the highest proportion of students from low socio-economic communities.

2 The University of Otago is New Zealand's first University founded in 1869 . Over $80 \%$ of its student body have original homes of residence outside of the Otago region, making it the most residential-intensive University in New Zealand.
} 
guided by a Pacific methodology known as Talanoa ${ }^{3}$. Talanoa, as a specific form of communication, is similar to that of interviewing and refers to "a conversation, a talk, an exchange of ideas or thinking whether informal or formal" that is usually carried out face to face (Vaioleti, 2006, p. 23). Talanoa allows for flexibility of dialogues and conversations between researchers and participants. It places the power in the relationship between a researcher and participants in their encounters throughout the Talanoa or interview process.

A comparative approach was used to illuminate both the barriers and enablers that promoted or impeded academic success for first year students. The student cohort was split into two groups according to a prescribed achievement level. Achievement can be measured as percentage of papers passed (PPP) or by grade point averages (GPA). The University of Otago's Academic Progress Policy uses PPP as a measure of student performance, with those students passing less than half of their papers in the first year, falling under this policy. PPP was used as a measure of first-year achievement and compared the experiences of students who did not complete $50 \%$ of their academic papers $(46.8 \%)$ with that of the students who were able to complete at least half of their academic papers $(53.2 \%)$.

Ethical approval was obtained from the University of Otago Ethics Committee. All participants were provided with an information sheet and consent forms were confirmed at the beginning of each interview. Students were made aware that their participation was voluntary and were welcome to decline and/or withdraw from the study at any stage and assured that their identities would remain confidential and anonymous.

\section{Participants and recruitment}

A total of 116 students met the eligibility criteria with 51 students allocated into Group 1 - as those students who did not pass $50 \%$ of their academic papers; and 65 students in Group 2 - as those students who did pass $50 \%$ of their academic papers. The inclusion criteria for eligible participants were: having enrolled as a full time first year undergraduate student at the University of Otago in 2013; identifying as an indigenous Pacific student; and a domestic student. Those who were excluded, were international students and students who had enrolled in a Foundation or bridging program in 2013. All eligible students were invited to participate in the study via email and post. In some instances, text messaging, using the social media platform Facebook and using Pacific student and community networks to facilitate face-to-face meetings, were employed as strategies to connect with participants, especially for those students who had left the University of Otago and/or were no longer residing in Dunedin city. Table 1 summarises the demographic profile of the participant cohort.

\section{Data collection}

The Talanoa research framework (Vaioleti, 2006) guided the interactions; as a Pacific indigenous process it allows for flexibility in delivery, and space for the layers of discussion that needed to occur. An interview guide was developed to guide the discussions but opportunities for participants to elaborate on certain questions and initiate their own issues for discussion, were readily made available throughout the interview process, with no time limit set for talanoa. Data was collected using oneon-one semi-structured interviews, by face-to-face and telephone. An important research strategy was to try to match the interviewer with participants as much as possible, in terms of demographic characteristics. In this case, a young post-graduate (Masters) Pacific student was employed, who was an active member of the Pacific student community at this university, to carry out the interviews. Data collection continued until data saturation point was reached.

Initial discussion questions were developed after consultation with University of Otago student

${ }^{3}$ Talanoa - Samoan and Tongan word for conversation, discussions or talking together. 
support staff and Pacific academic staff. The questions were framed taking into consideration previous literature reviews on Pacific students' tertiary education experiences in New Zealand and the wider Pacific region. The interview question guidelines consisted of a series of broad questions on: students' prior expectations of university study; support services; social life and Dunedin city; prior knowledge and expectations of the University of Otago; and their first-year university experience in 2013, identifying both successful/positive and unsuccessful/negative experiences and how these impacted on academic success.

Interviews were held at various booked office spaces at the University of Otago. Students were gifted with an alofa (gift) \$25 supermarket voucher as a token of appreciation. All interviews were audio recorded and transcribed. Transcripts, along with audio recordings, were stored safely and securely in University computer filing systems with access restricted to research personnel.

\section{Data analysis}

Qualitative data analysis drew upon a thematic analysis framework. Thematic analysis is often described as a "method for identifying, analysing and reporting patterns (themes) within data" (Braun \& Clarke, 2006, p. 79). It involves identifying underlying systems of meanings within a data set, the generation of codes and subsequently themes, that structure the presentation of findings. Using the computer software Nvivo an inductive approach was adopted to code data where unitising and coding occurred simultaneously. As each transcript was reviewed, meaningful comments were identified as units and labelled with a code. Generated codes were further examined in order to identify broader patterns. Emerging patterns from the collated data were categorised into themes and sub-themes reflective of the raw data and the project's objectives. Coded data and identified themes were re-read and cross examined between two Pacific research personnel.

\section{Findings}

Consistent with the overall 2013 cohort of first-year Pacific students at the University of Otago, the study participants were almost entirely aged under 25 , with slightly more females represented in the sample (Table 1). Compared with the overall 2013 cohort, the proportion of Cook Islands and Tongan students was slightly higher, while there was a slightly lower proportion of Samoans. The proportion of students who had returned to university was also slightly over-represented in the study sample when compared with the 2013 cohort. There were no differences between Group One and Group Two students in terms of age and gender. Samoan students were represented more highly in Group Two and Fijian students were represented more highly in Group One. 
Table 1: Demographics of study participants.

\begin{tabular}{|c|c|c|c|c|c|c|c|c|c|}
\hline & \multicolumn{2}{|c|}{2013 cohort } & \multicolumn{2}{|c|}{$\begin{array}{c}\text { Study } \\
\text { participants }\end{array}$} & \multicolumn{2}{|c|}{ Group $1^{a}$} & \multicolumn{2}{|c|}{ Group $2^{b}$} \\
\hline & & $\mathbf{N}$ & $\%$ & $\mathbf{N}$ & $\%$ & $\mathbf{N}$ & $\%$ & $\mathbf{N}$ & $\%$ \\
\hline Total & All & 116 & 100 & 66 & 100 & 23 & 100 & 43 & 100 \\
\hline \multirow[t]{2}{*}{ Age } & Under 25 & 105 & 91 & 62 & 94 & 23 & 100 & 40 & 93 \\
\hline & $25+$ years & 11 & 10 & 4 & 6 & 0 & 0 & 3 & 7 \\
\hline \multirow[t]{2}{*}{ Gender } & Male & 52 & 45 & 24 & 36 & 16 & 68 & 17 & 39 \\
\hline & Female & 64 & 55 & 42 & 64 & 7 & 32 & 26 & 61 \\
\hline \multirow[t]{6}{*}{ Ethnicity $^{\mathrm{c}}$} & Samoan & 46 & 40 & 25 & 37 & 5 & 21 & 20 & 46 \\
\hline & $\begin{array}{l}\text { Cook } \\
\text { Islands }\end{array}$ & 26 & 22 & 15 & 23 & 5 & 24 & 10 & 23 \\
\hline & Tongan & 22 & 19 & 15 & 23 & 7 & 29 & 9 & 20 \\
\hline & Niuean & 6 & 5 & 5 & 8 & 3 & 12 & 3 & 6 \\
\hline & Fijian & 18 & 16 & 9 & 13 & 6 & 27 & 3 & 6 \\
\hline & Other & 4 & 9 & 2 & 3 & 0 & 0 & 4 & 9 \\
\hline \multirow{2}{*}{$\begin{array}{l}\text { Enrolled } \\
\text { in } 2014\end{array}$} & No & 52 & 45 & 24 & 36 & 15 & 65 & 3 & 7 \\
\hline & Yes & 64 & 55 & 42 & 64 & 8 & 35 & 40 & 93 \\
\hline
\end{tabular}

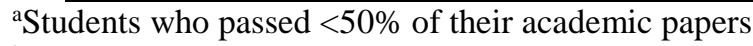

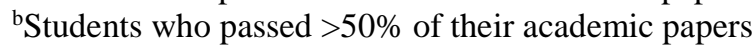

${ }^{c}$ Students who reported more than one ethnic group are counted once in each group reported and the sum of individual groups may add up to more than $100 \%$.

The factors enabling and impeding academic success for first-year Pacific students are presented in Table 2. The factors found to both enable and impede student achievement are grouped under three headings; (i) Institutional, (ii) Family/Community and (iii) Individual. Taking a lead from Bronfenbrenner's (1986) socio-ecological framework, which proposes that human development, occurs and is influenced by the interactions between an individual and their environmental settings or systems, the headings define the spheres of influence on a student's university experience: (i) institutional; (ii) family and community groups; (iii) individual. Findings related to the 'institutional' environment included factors that are under the control of the university, such as its physical setting, programs, teaching practice, resources and academic workload. 'Family and community' factors are related to groups that students may be affiliated with, such as family, a church community, school community, specific Island communities (e.g., Samoan community, or Tongan or Cook-Island community) and friendship/peer groups. Reported enablers and barriers at the 'individual' level are related specifically to a participant and their personal skills and characteristics.

Additionally, the findings are grouped under two subheadings; Academic and Social. The first year of higher education is often referred to by international studies as a transition period. Within an educational context, common transition examples include: when students encounter new knowledge, such as new subject material; move between educational stages, such as secondary school to university; and adapt to different physical institutional contexts, for example, moving from living at home to living in a residential hall (McInnis, 2000). Entering the University of Otago is a noteworthy transition, as students face various changes and challenges in leaving home and adjusting to new learning environments. Successful adaptation to both academic and social transitions is significant in determining achievement in higher-level tertiary education. The factors that influence students' study 
and learning transition are grouped under the subheading Academic and the factors that relate to lifestyle transitions as part of the first-year experience, are grouped under the subheading Social.

In Table 2 below, factors that were identified by Group One students as barriers or enablers affecting their university first-year experience, are highlighted in orange. Factors identified by Group Two students as barriers or enablers affecting their University experience are highlighted in green and italicised. Factors that were commonly identified by both Group One and Group Two students are highlighted in blue with bold font.

Table 2: Barriers and enablers for academic achievement of first year Pacific students at the University of Otago,2013.

\begin{tabular}{|c|c|c|c|}
\hline \multicolumn{2}{|c|}{ Key to presentation of data in Table 2: } & \multicolumn{2}{|c|}{ Group 1 students $=$ passed $<50 \%$ academic papers } \\
\hline & & \multirow{2}{*}{\multicolumn{2}{|c|}{$\begin{array}{l}\text { Group } 2 \text { students }=\text { passed }>50 \% \text { academic papers } \\
\text { Both Group } 1 \text { and Group } 2 \text { students }\end{array}$}} \\
\hline & & & \\
\hline \multicolumn{4}{|c|}{ Barriers } \\
\hline \multirow{4}{*}{ : } & Institutional & Family/Community/Friends & Individual \\
\hline & $\begin{array}{l}\text { - New learning environment } \\
\text { - Academic adjustment }\end{array}$ & $\begin{array}{l}\text { - Family and Community } \\
\text { expectations (internalised } \\
\text { pressure) }\end{array}$ & \multirow{2}{*}{$\begin{array}{l}\text { - Time management } \\
\text { - Lack of coping strategies } \\
\text { - Lack of use of student } \\
\text { support services } \\
\text { - Lack of effective study } \\
\text { strategies }\end{array}$} \\
\hline & $\begin{array}{l}\text { - Lack of awareness of student } \\
\text { support } \\
\text { - Non-residential college } \\
\text { accommodation }\end{array}$ & & \\
\hline & $\begin{array}{l}\text { - Lack of Pacific support in non- } \\
\text { Health Sciences divisions } \\
\text { - Confidentiality at support } \\
\text { services }\end{array}$ & $\begin{array}{l}\text { - Backlash from non-Pacific } \\
\text { peers regarding use of Pacific } \\
\text { support services }\end{array}$ & \\
\hline 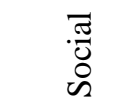 & Drinking culture & & - Living independently \\
\hline
\end{tabular}

Enablers

\begin{tabular}{|c|c|c|c|}
\hline \multirow{3}{*}{$\frac{0}{\frac{0}{0}}$} & Institutional & Family/Community/Friends & Individual \\
\hline & $\begin{array}{l}\text { - University support } \\
\text { - Departmental support } \\
\text { - Tutorials }\end{array}$ & - Family support & $\begin{array}{l}\text { - Student expectations } \\
\text { - Positive learning } \\
\text { strategies }\end{array}$ \\
\hline & - Pacific support services & $\begin{array}{l}\text { - Family member attended } \\
\text { university }\end{array}$ & $\begin{array}{l}\text { - Seeking help early } \\
\text { - Positive study habits }\end{array}$ \\
\hline \multirow{2}{*}{$\begin{array}{l}\bar{\pi} \\
. \frac{\pi}{0} \\
0\end{array}$} & - University friendships/peer & $\begin{array}{l}\text { - University friendships/peer } \\
\text { support }\end{array}$ & $\begin{array}{l}\text { - Gap year } \\
\text { - Mature student }\end{array}$ \\
\hline & 4 & $\longrightarrow$ & - Balanced healthy lifestyle \\
\hline
\end{tabular}

Note:

indicates that University friendships/peer support groups can be formed both as a result of an existing group prior to University study or as a result of the influence of the University, via University social events, orientation activities, Halls of Residence peer group, student associations etc.

This project's findings suggest that the determinants of academic success and achievement for this cohort of Pacific students include institutional, family/community and individual factors. Both groups 
of students highlighted the following barriers: adjusting to the new tertiary learning environment; academic adjustment; and the internalised pressure from family/community expectations. In particular, students identified the differences in academic workload between high school and university as a barrier which could lead to their struggling and falling behind with the course workload, as well as having difficulty navigating self-directed study and understanding course expectations.

So much content, like what you get in like a week at Uni is like a term in high school, I swear. So then it was like, you just fall behind and it was like how do I even catch up from here. (Participant 3)

The autonomous, self-directed and independent learning environment that underpins university education was reported as challenging by these first year Pacific students. Bigger classes, reduced academic monitoring by teaching staff, understanding assessments and communication with teaching staff around feedback, were all mentioned as facets of the new learning environment that were challenging for them.

Getting to class is all good but like after that, you get your own independent time and trying to manage that and making sure you understand everything on your own was hard. (Participant 4)

Family and community expectations were identified as sources of internalised pressure, particularly among Group One students. These included expectations of students to do well academically and to complete a degree that would lead to a job.

It was sort of expected that I had to go to university so that's all pressure from school, a little bit of parents, but driven from that, to go university because I was in a leadership role. There was so many outside influences, [expecting] that I do well at Uni. They keep asking 'How's Uni going?' and stuff, so that sort of put a bit of pressure. (Participant 18)

A number of similar positive enablers were reported by both groups of students. Academic factors, such as university support that included tutorials and departmental support, were identified by most study participants in both groups as being helpful for their academic study.

Discussing and talking to the lecturers about what I was unclear about during discussions or during reading the readings and they were really helpful, especially Dr. X from Theology. He's really like an approachable person and he's really nice and um yeah he just tells me to just keep reading and just take it slow because sometimes scan reading doesn't help. (Participant 8)

Additional tutorials were also identified as a positive aspect of the learning experience at university. These provided a space for students to ask questions and discuss learning material in a smaller and less intimidating setting. These tutorials were accessible through different support services such as the Pacific students' support services, the Student Learning Centre and academic departments.

Non-academic factors, such as having family support, university friendships and peer groups for support, also played a positive role in the academic achievement and university experiences of both groups of Pacific students.

I had a patch where I was like, I had no motivation to study and I don't know what to do. I called home 'Mum, I need a kick up the $a^{* * *}$, like help me', and then she like texted me, 'Think about all the times you've spent away from your sisters and think about the reason why you're there, like all this time away from your family, you know it's going to be worth it in the end.' You know, she wasn't putting on pressure and I was like, 'oh yeah, that's true!' and I was like, right! And I was like sweet. (Participant 8)

Key differences between the two groups of students in reported barriers and enablers were noted at the institutional and individual level. At the institutional level, Group One students reported a lack of awareness of student support services as a barrier, also not living in a residential college. Group One 
students talked about only becoming aware of university support services after semester one, when receiving poor academic results. There appeared to be a lack of early utilisation of academic support services, with students being fakama or shy and not wanting to be viewed by their peers and academic community as needing help. Alongside this was a fear of negative judgement.

I don't know why I didn't [seek help], I think I was just scared of people being like 'You haven't done well' and I just didn't want to be shut down. (Participant 44)

I think I feel scared to ask for help, I feel I'll be judged. I know I won't be because not all of them are like that, but that's just me. (Participant 40)

There were a lot of times where I thought, I would just deal with it myself like, it's okay, I'll just, I'll like look it up or I'll go to the library and I'll figure it out cause you, I don't know I guess you feel like, like you feel stupid when you ask. (Participant 11)

Barriers to accessing academic support, such as additional tutorials, were reported by students who were living in off-campus accommodation or living with family in their first year of study. Not living in close proximity to their peers was noted as a further barrier for forming study groups, compared with living in a residential college, where there are more opportunities to form study groups with peers.

It was hard for me first not being at a hall cause everyone that was at a hall would be together, they would study together and stuff, yeah. In my first year I didn't really talk to anyone or I kinda just tried to do it on my own. (Participant 11)

At the individual level, time management, lack of effective coping strategies, lack of use of student support services and poor study strategies, were impeding factors for Group One students. Notable was the lack of effective coping strategies when encountering academic disappointments, such as failing papers or not gaining entrance into a particular restricted academic program. Students often dealt with such stress factors in negative and unhealthy ways, including drinking alcohol and ignoring the problems. Dealing with the academic demands of university was particularly challenging for students who did not seek help early. These students reported seeking help only once a point of crisis was reached, and then in a reactionary capacity rather than as a prevention.

I guess it was depressing knowing about my academic things and stuff but then I would be like, YOLO!'. (Participant 12)

When I, like get a grade that wasn't really good, then I'm the kinda person that if I'm stressed, I won't really do anything. I would not freeze but I let it go, and I don't do anything about it and hoped it will go away. (Participant 19)

There were two unique positive enabling factors for Group One students noted at the individual level; taking a gap year and being a mature student were both noted as positives. These students indicated that having more experiences with other adult environments allowed more personal confidence to grow, developing greater abilities to deal with new people and places.

For Group Two students, enablers they identified that were unique to them and not exhibited by Group One students, tended to be related to the individual level and included: realistic expectations; positive learning strategies; seeking help early; and having a balanced healthy lifestyle. These students highlighted the importance of being proactive about seeking help, accessing, and utilising available student support services.

\footnotetext{
${ }^{4}$ Yolo - 'You only live once': expressing the view that one should make the most of the present moment without worrying about the future, and often used as a rationale for impulsive or reckless behaviour (Defined in Oxford Dictionary https://en.oxforddictionaries.com/definition/yolo)
} 
We must have not understood something said to us at the start of Commerce or something and I said 'well let's just go get some help because, we're paying $\$ 800$ per paper, surely, they're here to help us! (Participant 3)

I got a C-on the first test of my university year and I just passed and I was like, okay I need to go see someone, this is not a joke. Like I need to go see someone like ASAP. So I just thought, if I'm not going to ask for help, like how am I going to get through this, you just have to like kinda just do it.

(Participant 43)

Another unique enabler reported by Group Two students was having a past family member attend university, which seemed to lead to a greater awareness about university prior to starting. Group Two students seemed to be more knowledgeable about the challenges that underpinned university study, such as the academic workload, bigger classes, self-directed learning and the student culture. Understanding the nature of the university as a different learning institution appeared to assist Group Two students to raise their self-expectations, in order to cope with the new learning environment. As illustrated below, some students mentioned personal expectations of themselves to do their best.

What you hear about the University culture and stuff, it sounds fun. What I sort of expected of myself in coming down, was like doing the best I can. I don't know, it sounds really simple but it was really just that, it was to come down and like make sure that you weren't too distracted. (Participant 11)

Another important enabling factor that was unique to the successful Group Two students, is identified at the institutional level - that is, using specific-Pacific student support services.

We had the tutorials in the PIC [Pacific Island Centre - a Pacific student support unit] so normally I would ask the tutor there, yeah instead of going to the lecturer or head of department for help, I would just usually go to email help to the PIC, cause I felt more comfortable with the PI tutor. (Participant 23)

In terms of barriers unique to Group Two students, students who utilised Pacific support services throughout their studies reported receiving peer backlash and being questioned by their fellow nonPacific students around the existence of Pacific support services and programs, particularly in the first year of study. These peer questioning interactions affected their use of Pacific student services.

After first year, none of my friends went to tutes [tutorial classes] or anything like the [Pacific group] extra ones. You can just tell, all my friends are European, you can just tell that they felt like that it was like an unnecessary thing that we got as like an extra. So they felt like that was like an extra thing that they didn't get, so like [they say] 'why do we have that sort of thing? (Participant 14)

\section{Discussion}

This project's findings indicate that the determinants of academic success and achievement for firstyear Pacific students included institutional, family/community and individual factors. The study was able to identify particular aspects of the first-year university experience that can be described as transitional and requiring students' greater adaptation in the first-year, in order to be successful. Previous studies have confirmed the importance of achieving success in the first year of study as a precursor for successful completion (Chu et al., 2013; Madjar et al., 2010). This study confirmed that students who used university academic support structures, and especially the Pacific-centric student support services, achieved more highly academically than students who did not; these findings are consistent with results found by others (Anae et al., 2002; Penn, 2010).

The differences in help-seeking behaviours between Group One and Group Two students may lie in their different expectations of university study. Group Two students in particular, were not first in their family to attend university, hence past family members' experiences appeared to have positively influenced their expectations of university and their study habits. A likely recommendation for tertiary institutions is to develop ways to confidentially identify first-in-family students in order to 
place greater emphasis on supporting these students' academic and social transitions into university environments (Davidson-Toumu'a \& Dunbar, 2009).

Previous data suggest that Pacific students may be disproportionately represented in the first-infamily category to attend university (Benseman et al., 2006; Meehan, 2017). Developing a Pacificcentric short university preparation course could help to address the academic and social barriers that negatively influence Pacific students' first year academic success. Previous research in the New Zealand context supports bridging transitions between secondary and tertiary study for minority students (Madjar et al., 2010). To date, the authors of this paper are unaware of documented educational interventions that currently address this for minority students in New Zealand.

The findings from this research suggest that there is a place for a Pacific-centric short university preparation program which encourages and normalises help-seeking behaviour, and works to reduce any stigma attached to help-seeking behaviours for Pacific students. Such a program could also address resilience factors, including tools for dealing with peer-backlash, encouraging realistic expectations for university study and challenges, promoting student support options and strengthening student engagement in the first year. There is also the potential for a pre-degree program to address Pacific families' engagement and capacity building, so that they are better able to provide their children with the family support required.

At the institutional level, the issue of Pacific students encountering peer-backlash for the use of Pacific student support services, and the subsequent negative impact upon future help-seeking behaviours, can be countered in several ways, including: (1) cultural competency training for university staff who work with and engage with Pacific students, whether in teaching or support services; and (2) curriculum development to ensure academic content includes aspects of the Pacific world.

Such measures are likely to have a two-fold effect: (i) increasing Pacific students' understanding of and transition into the university environment; and (ii) raising awareness among non-Pacific students of the diverse realities of Pacific students. A final point is that university leaders need to champion Pacific governance and leadership in tertiary education, to support practices that benefit Pacific students, and to drive institutional changes to address educational disparities (Coxon et al., 2002; Tongati'o, 2010; Toumu'a \& Laban, 2014).

\section{Conclusion}

This study found that students who succeeded in the first year of study used Pacific-centric student support services, had family members who had been to University before, and had different study habits, learning strategies and expectations, when compared with their peers who struggled to achieve. As first-year academic success is a strong predictor of university completion, this study recommends future effort in first year transition interventions to address the social and academic adaptations that Pacific students need to make in order to be successful at university study.

Identifying and addressing the factors that impede academic success for minority students in higher education is a global priority, particularly for countries experiencing rapid changes in university population diversity. This study contributes important perspectives on the first-year transition for Pacific students, and offers recommendations for tertiary institutions on ways to ameliorate some of the barriers students face, thereby enhancing their engagement and future academic success. 


\section{References}

Anae, M., Anderson, H., Benseman, J., \& Coxon, E. (2002). Pacific peoples and tertiary education: Issues of participation. Final report. Auckland, New Zealand, University of Auckland.

Airini, B. D., Curtis, E., Johnson, O., Luatua, F., O'Shea, M., Rakena, T., Reynolds, G., Sauni, P., Smith, A., Huirua, T.S., Tawara, M., Townsend, S., Savage, T., \& Ulugia-Pua, M. (2010). Success for all: Improving Māori and Pasifika student success in degree-level studies. Auckland, New Zealand: University of Auckland.

Benseman, J., Anae, M., Anderson, H., \& Coxon, E. (2002). Pacific peoples and tertiary education: Issues of participation. Wellington, Ne Zealand: Ministry of Education.

Benseman, J., Coxon, E., Anderson, H., \& Anae, M. (2006). Retaining non-traditional students: lessons learnt from Pasifika students in New Zealand. Higher Education Research \& Development, 25(02), 147-162.

Braun, V., \& Clarke, V. (2006). Using thematic analysis in psychology. Qualitative research in psychology, 3(2), 77-101.

Bronfenbrenner, U. (1986). Ecology of the family as a context for human development: Research perspectives. Developmental Psychology, 22(6), 723.

Coxon, E., Anae, M., Mara, D., Wendt-Samu, T., \& Finau, C. (2002). Literature review on Pacific education issues. Auckland, New Zealand: University of Auckland.

Chu, C., Abella, I. S., \& Paurini, S. (2013). Educational practices that benefit Pacific learners in tertiary education. Wellington: AKO Aotearoa. Retrieved from https://akoaotearoa.ac.nz/project/pasifika-learners-and-successtertiaryeducation/resources/files/educational-practices-benefit-pacific-learners-tertia-1.

Davidson-Toumu'a, M. R., \& Dunbar, K. (2009). Understanding the experiences of Pacific students and facilitating sociocultural adjustment into higher education in Aotearoa, New Zealand. Journal of the Australia and New Zealand Student Services Association, 33, 69-88.

Frey, J. H., \& Fontana, A. (2005). The interview: From neutral stance to political involvement. The Sage Handbook of Qualitative Research, 695-726.

Hillman, K. (2005). The first year experience: The transition from secondary school to university and TAFE in Australia. LSAY Research Reports, 44.

Horrocks, J., Ballantyne, N., Silao, A., Manueli, K., \& Fairbrother, P. (2012). Success for Pacific learners: The impact of tertiary education strategies. Wellington: AKO Aotearoa. Retrieved from https://akoaotearoa.ac.nz/download/ng/file/group-5331/success-for-pacificlearners-the-impact-of-tertiaryeducation-strategies.pdf.

Kidwell, K. S. (2005). Understanding the college first-year experience. The Clearing House: A Journal of Educational Strategies, Issues and Ideas, 78(6), 253-256.

Kokaua, J., Sopoaga, F., Zaharic, T., \& van der Meer, J. (2014). The development of a pre-enrolment screening tool to inform targeted support services in the first year in health sciences. The International Journal of the First Year in Higher Education, 5(1), 55-66.

Kvale, S., \& Brinkmann, S. (2009). Learning the craft of qualitative research interviewing. Thousands Oaks: Sage Publications.

Luafutu-Simpson, P., Moltchanova, E., O'Halloran, D., Petelo, L., \& Uta'i, S. (2015). Change strategies to enhance Pasifika student success at Canterbury tertiary institutions. Wellington, New Zealand: AKO Aotearoa.

McInnis, C., James, R., \& Hartley, R. (2000). Trends in the first year experience: In Australian universities. Canberra: Department of Education, Training and Youth Affairs.

Madjar, I., McKinley, E., Deynzer, M., van der Merwe, A. (2010). Stumbling blocks or stepping-stones? Students' experience of transition from low-mid decile schools to university. Auckland, New Zealand: Starpath Project, University of Auckland.

Mayeda, D. T., Keil, M., Dutton, H. D., \& 'Ofamo'oni, I. (2016). "You've gotta set a precedent": Māori and Pacific voices on student success in higher education. Alternative, 10(2), 165-179.

Meehan, L., Pacheco, G., \& Pushon, Z. (2017). Explaining ethnic disparities in bachelor's qualifications: Participation, retention and completion in NZ. Wellington, New Zealand: New Zealand Productivity Commission.

Millward, P., Stephenson, M. S., Rio, N., \& Anderson, H. (2011). Voices from Manukau: Recruitment and success of traditionally under represented undergraduate groups in New Zealand. Asia Pacific Education Review, 12(2), 279-287. 
Ministry of Education (2013). Pasifika education plan 2013-2017. Wellington, New Zealand The New Zealand Government. Retrieved from https://education.govt.nz/ministryof-education/overall-strategies-andpolicies/pasifika-education-plan-2013-2017/.

Ministry of Education (2015). Profile \& trends 2015: Tertiary education outcomes and qualification completions. Wellington, New Zealand: The New Zealand Government.

Ng Shiu, R. (2011). "It's like going to the moon": The experiences of Samoan tertiary health students at the University of Auckland. (Unpublished doctoral thesis). University of Auckland, Auckland NZ.

Penn, R. (2010). Manumalo: A study of factors which facilitate success for New Zealand-born Samoan students at university (unpublished master's thesis). Auckland University of Technology, Auckland, New Zealand.

Perrot, A. R. D. (2015). Overcoming challenges: Pacific students' experiences of being resilient through tertiary education (unpublished Masters Thesis). Victoria University of Wellington, Wellington, New Zealand.

Statistics New Zealand (2014). 2013 census quick stats about culture and identity. Wellington, New Zealand : The New Zealand Government.

Sopoaga, F., Zaharic, T., Kokaua, J., Ekeroma, A.J., Murray, G., \& van der Meer, J. (2013). Pacific students undertaking the first year of health sciences at the University of Otago, and factors associated with academic performance. The New Zealand Medical Journal, 126(1384), 96-108.

Southwick, M., Scott, W., Mitaera, J., Nimarota, T., \& Falepau, L. (2017). Articulating a pedagogy of success for Pacific students in tertiary education. Ako Aotearoa: Wellington

Tertiary Education Commission (2014). Tertiary education strategy 2014-2019. Wellington: The New Zealand Government.

Tertiary Education Commission (2017). Pasifika operational strategy 2017-2020. Wellington: The New Zealand Government.

Teu, A. (2014). The barriers, enablers and influences around the transition to university experiences of Pacific students in the health sciences first year program at the University of Otago. Unpublished Masters Dissertation. University of Otago, Dunedin, New Zealand.

Tinto, V. (2006). Research and practice of student retention: What next? Journal of College Student Retention: Research, Theory and Practice, 8(1), 1-19

Tinto, V. (2008). Learning better together: The impact of learning communities on the persistence of low-income students. In Opportunity Matters.

Tongati'o, L. P. (2010). Ko e fanā fotu': Success in motion, transforming Pasifika education in Aotearoa New Zealand 1993-2009 (unpublished doctoral thesis). University of Canterbury, Christchurch, New Zealand.

Toumu'a, R., \& Laban, L. W. (2014). Cultivating a whole of university response to Pasifika: Research in action for widened participation, retention and completion at Victoria University of Wellington, New Zealand. International Studies in Widening Participation, 1(2), 46-59.

Vaioleti, T. M. (2006). Talanoa research methodology: A developing position on Pacific research. Waikato Journal of Education, 12(1).

Yorke, M. (2000). Smoothing the transition into higher education: What can be learned from student noncompletion. Journal of Institutional Research, 9(1), 35-47.

Zepke, N., Leach, L., \& Butler, P. (2011). Non-institutional influences and student perceptions of success. Studies in Higher Education, 36(2), 227-242.

The authors may be contacted via:

tasileta.teevale@otago.ac.nz

\section{Please cite this paper as:}

Teevale, T, \& Teu, A. (2018). What enabled and disabled first-year Pacific student achievement at University? Journal of the Australian and New Zealand Student Services Association, (26)1, 15-27.

https://doi.org.10.30688/janzssa.2018.04 